\title{
OUTCOMES OF TRANSRADIAL APPROACH IN PATIENTS UNDERGOING PRIMARY PERCUTANEOUS CORONARY INTERVENTION FOR ACUTE ST SEGMENT ELEVATION MYOCARDIAL INFARCTION
}

\author{
Amna Rashdi, Ayaz Ahmad, Jahanzab Ali, Ahmad Usman, Syed Khurram Shahzad, Atiq Ur Rahman \\ Army Cardiac Center Lahore/National University of Medical Sciences (NUMS) Pakistan
}

\begin{abstract}
Objective: An experience to evaluate the outcomes, feasibility, effectiveness and safety of transradial approach practice in patients undergoing primary percutaneous coronary intervention for acute ST elevation Myocardial infarction in Army Cardiac Centre.

Study Design: Descriptive cross-sectional study.

Place and Duration of Study: Army Cardiac Centre, Lahore, from Jan 2020 to Mar 2020.

Methodology: All patients undergoing primary percutaneous coronary intervention via transradial approach for acute ST elevation Myocardial infarction were included. Informed consent was taken signed. Demographic characteristics, risk factors, time variables like arterial access time, door to balloon time and procedural success was determined.

Results: Out of enrolled patients in study, frequency of males and females were 49 (82\%) and 9 (18\%) respectively. The mean age was $57 \pm 10.86$ years ranging from 30 to 75 years. On admission, $25(50 \%)$ were hypertensives, $20(40 \%)$ had diabetes and $18(36 \%)$ were smokers. The initial choice for primary percutaneous coronary intervention was transradial approach in all patients, right side $49(98 \%)$ and left side $1(2 \%)$. Due to failure to achieve radial access transfemoral and homolateral ulnar approach was adopted $2(4 \%)$ and $1(2 \%)$ respectively leading to $96 \%$ success and $4 \%$ failure for transradial access. The main infarcted artery was LAD 31 (62\%) followed RCA $15(30 \%)$ Time to arterial access time was 2 mins, door to balloon 34 mins. Eighty percent complication free transradial approach was achieved, $8(16 \%)$ patients had pain and $2(4 \%)$ developed hematoma.

Conclusion: Our results proved Transradial approach for primary PCI as a safe, feasible and cost effective procedure.
\end{abstract}

Keywords: Primary percutaneous coronary intervention, ST elevation myocardial infarction, Transradial approach.

This is an Open Access article distributed under the terms of the Creative Commons Attribution License (http://creativecommons.org/licenses/by/4.0), which permits unrestricted use, distribution, and reproduction in any medium, provided the original work is properly cited.

\section{INTRODUCTION}

Cardiovascular diseases (CVD) are main of cause of mortality and morbidity globally. The incidence of the diseases is increasing day by day. In 2015, approximately 17.7 million people died from Coronary Artery disease (CAD) which makes $31 \%$ of death population worldwide. It is expected that till 2030, $43.9 \%$ of population in United States is at risk of developing cardiac diseases ${ }^{1}$. Similar is the case in other countries like in Saudi Arabia, the united Arabic Emirates, Bahrain and Qatar where rate of mortality due to CVD is $42 \%$, $38 \%, 32 \%$ and $23 \%$ respectively ${ }^{2}$. Pakistan is of no

Correspondence: Dr Amna Rashdi, Cardiology Department, Army Cardiac Center, Lahore Pakistan exception and there is epidemiological transition occurred making CVD as main cause of sudden death $^{3}$. Among CAD, ST elevation myocardial infarction (STEMI) is a major concern highlighting to $56 \%$ cause of total acute myocardial infarction cases in Pakistan and $25-40 \%$ of STEMI in acute coronary syndrome cases worldwide ${ }^{4,5}$.

The main goals required in the management of STEMI is early diagnosis and adopting rapid appropriate choice of reperfusion. Several studies have shown that achieving such targets resulted in better outcomes and decreased rate of fatality ${ }^{6}$. According to recent guidelines of reperfusion, Primary Percutaneous coronary Intervention (PPCI) is the standard option of treatment in acute STEMI ${ }^{7,8}$. PPCI is defined as a procedure to 
intervene for diseased culprit artery within 12 hours of chest pain with no thrombolysis earlier.

The next important step in the management of Acute STEMI after diagnosing and planning for reperfusion mode is choice of access site for PPCI. There are various routes femoral, brachial, ulnar, transradial and distal radial artery via snuff box for cardiac catheterization, most commonly used method for PPCI is transfemoral worldwide. The transfemoral access (TFA) in intervention cardiology is preferred because of limited use of contrast material, reduce radiation time and easy accessibility. However, from the last two decades, transradial access (TRA) is gaining popularity and due to its reduced vascular complications and better outcomes in acute STEMI ${ }^{9}$. It has been reported in several trials that there is lower risk of bleeding with anticoagulation in STEMI patients with TRA than TFA ${ }^{10-12}$.

TRA was first described by Dr. Lucein Campeau for diagnostic purpose in 1989 and in 1993, Dr. Ferdinand Kiemeneij used this technique for intervention ${ }^{13}$. According ESC guidelines of reperfusion, TRA is class II A, level B recommendation for $\mathrm{PPCI}^{14}$. TRA has many advantages which favours the transition from TFA in angioplasty. TRA has lower bleeding risks leading to hematoma, pseudo hematoma, low cost, early discharge and reduced fatality. Irrespective of convincing evidences favouring TRA, there is disparity in adopting this approach across the world. As per latest literature review In United States of America TRA is being opted for PPCI nowadays but its preference depends on interventionist, cardiac center and geographic location. Radial Artery access is more commonly used in Northeast and Midwest as compared to West and South America15. The rationale for underuse of TRA is multifactorial but delayed door to balloon time D2BT is a crucial factor.

TRA is more practiced in middle East and Asian countries. Numerous international studies validated the feasibility of TRA in STEMI with PPCI facility centres. Radial vs femoral access for coronary intervention (RIVAL) trial provides evidence in favour of TRA 16 . Our centre has recently started to offer PPCI to all suitable candidates presenting with acute STEMI. TRA is preferred in routine due to well experienced and trained operators comfortable with this approach. This study aims to share the experience of Radial access in PPCI encouraging this route due to less bleeding complications irrespective of intake of strong antiplatelets and anti-thrombotic. It also helped us to highlight the fact of its practicability in developing countries like Pakistan due to its safety and cost effectivity. To our knowledge non of the study has been done in Lahore so far.

\section{METHODOLOGY}

A descriptive cross-sectional study was conducted from January 2020 to early March 2020 in Army Cardiac Center, Lahore, after approval from institutional ethical committee. All appropriate patients suffering from acute STEMI presenting to Emergency Room was offered PPCI considering it as a gold standard treatment as well as thrombolysis with all pros and cons to educate and help them opt a better option for them. Candidates in acute STEMI for PPCI were as follows ${ }^{1}$. ST segment elevation on ECG with $>1 \mathrm{~mm}$ in two or more contiguous limb leads or $>2 \mathrm{~mm}$ in two or more contiguous precordial leads 7.2. presented with typical chest pain $<12$ hours without a previous history of thrombolytic therapy. PPCI procedure is also explained to the patient or accompanying attendants. Those who chose PPCI were included in this study after informed written consent. Other inclusion factors involve participants with positive Allen`s sign for transradial Primary Percutaneous intervention (TR-PCI). Exclusion criteria for this study was ${ }^{1}$. STEMI Patients contraindicated candidates for $\mathrm{PPCI}^{2}$. Negative Allen`s test ${ }^{3}$. Impalpable radial artery.

The preference of Right of left radial completely depended of the operator's choice. The patient lied in supine position on the table of catherization lab with trapezoid shaped board. The board is usually light weight made of fiberglass placed at shoulder level. Patient was 
prepared with right arm exposed and abducted at $70 \%$ and hyperextended wrist. Appropriate Aseptic measures were taken before starting the procedure. Next radial artery was palpated, and 2-3 $\mathrm{ml}$ of $1 \%$ lidocaine was administered as local anesthesia. Puncture was performed with 21G to $22 \mathrm{G}$ puncture needle at $30-45$ degree. 5 -F or $6 \mathrm{~F}$ radial Artery (RA) sheath was inserted after that. Heparin Injection of 5000 I.U were given after successful injection. Under fluoroscopy catheters and guidewires were passed through radial artery during PPCI.

All candidates for primary coronary intervention received tablet Aspirin 300 mg, clopidogrel $600 \mathrm{mg}$, high dose statins, heparin according to weight, two boluses of glycoprotein IIB IIIA inhibitor followed by its infusion. Drug eluting stents (DES) were preferred, however Bare metal stents were also an option and used as per operator`s discretion or circumstances. Following drugs like intracoronary nitroglycerine, adenosine, verapamil was used as per requirement to tackle any situation including spasm or no flow phenomena. Only culprit artery is treated, and staged PCI was planned for future.

Patients demographics including age, gender with detailed clinical history was taken. Co-morbid like hypertension, diabetes mellitus type II, smoking, hyperlipidemia was monitored. Diabetes mellitus was considered positive with HBA1c $>6.5 \%$. Hypertensives were those on anti hypertensives for at least 6 months. Hyperlipidemia was considered in those patients with total cholesterol $>200 \mathrm{mg} / \mathrm{dl}$, high density lipoproteins $<40 \mathrm{mg} / \mathrm{dl}$, Low density lipoprotein $>100 \mathrm{mg} / \mathrm{dl}$ or triglyceride $>150 \mathrm{mg} / \mathrm{dl}$.

Angiographic details including main culprit artery for the event, number of stent and type of stents. Procedural data includes time for arterial puncture access time, door to balloon time and procedural success. Arterial time is defined as time from arterial puncture to sheath insertion. Door to balloon time is from presentation of STEMI patient to ER to pass through the lesion from culprit artery and balloon insertion. procedural success of PCI was defined as achieving Thrombolysis in Myocardial infarction flow grade 3 in infarcted artery or $<10 \%$ residual stenosis, however procedural success for transradial approach is completion of procedure through Radial artery. Hematoma is clinical presentation of bleeding from the access site during puncture, wire insertion or after use anti platelets or anti coagulants. All patients were shifted to Cardiac Care Unit (CCU-1) for strict observation and discharged after 24 hours.

\section{RESULTS}

During the study period, a total of 50 patients underwent primary PCI for acute STEMI. All these patients were approached for transradial access initially, 49 (98\%) through right side while $1(2 \%)$ via left side. Due to failure to access through radial side, transfemoral (4\%) and homolateral ulnar site $(2 \%)$ was adopted making successful radial approach by $96 \%$ with $4 \%$ failure fig- 1 .

Males represented $82 \%$ while females were $18 \%$ of total which revealed comparatively higher

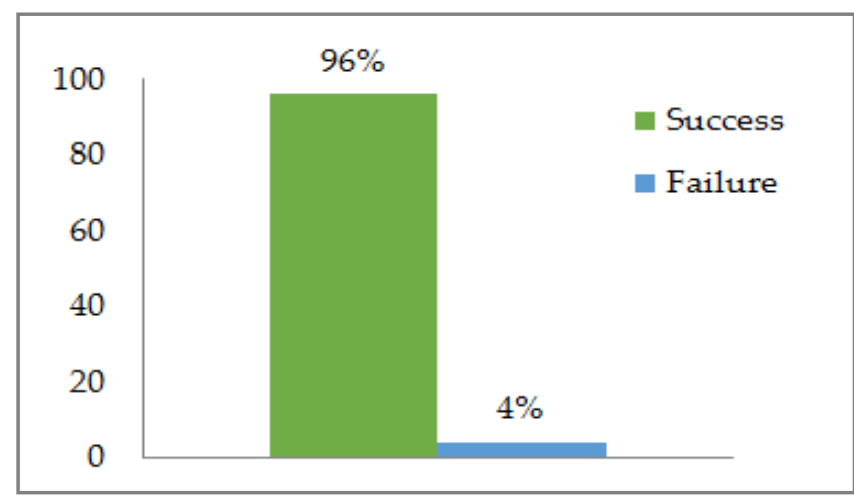

Figure-1: Description of success rate of transradial approach $(n=50)$.

Table-I: Demographic and risk factors $(n=50)$.

\begin{tabular}{|c|c|}
\hline 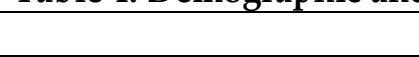 & n (\%) \\
\hline \multicolumn{2}{|l|}{ Gender } \\
\hline Male & $41(82 \%)$ \\
\hline Female & $09(18 \%)$ \\
\hline Hypertension & $25(50 \%)$ \\
\hline Diabetes Mellitus Type II & $20(40 \%)$ \\
\hline Smoking & $18(36 \%)$ \\
\hline Family History & $12(24 \%)$ \\
\hline Dyslipidemia & $9(18 \%)$ \\
\hline Previous History of CAD & $3(6 \%)$ \\
\hline
\end{tabular}


burden of STEMI in males. The mean age was 57 \pm 10.86 years ranging from 30 to 75 years. Demographic and risk factors were presented in table-I. Showing Hypertension as the main risk factor (50\%) and diabetes mellitus as second most common risk for STEMI. The mean arterial access time is 2 minutes while mean door to balloon time was 34 minutes. The angiographic and procedural findings are depicted in table-II.

Table-II: Angiographic and procedural findings $(n=50)$.

\begin{tabular}{l|c}
\hline \multicolumn{2}{|c}{ n (\%) } \\
\hline Vascular Access & $\mathrm{n}=50$ \\
Transradial Approach (Initial choice) & $49(98 \%)$ \\
Right & $1(2 \%)$ \\
Left & $2(4 \%)$ \\
\hline If radial access fails, next choice & $1(2 \%)$ \\
\hline Transfemoral & $31(62 \%)$ \\
Homolateral Ulnar & $4(8 \%)$ \\
\hline Infarcted related coronary artery & $15(30 \%)$ \\
\hline Left Anterior Descending (LAD) & \\
Left Circumflex (LCX) & $50(100 \%)$ \\
Right Coronary (RCA) & $0(0 \%)$ \\
\hline Types of Stent & $48(96 \%)$ \\
\hline Drug eluting stent (DES) & $2(4 \%)$ \\
\hline Bare metal stent (BMS)
\end{tabular}

The most common artery involved was Left anterior descending artery (62\%) followed by Right coronary artery (30\%). Drug-eluting stent was used in all patients. Majority of them had one $(96 \%)$ while only two patients required 2 stents placed in infarcted culprit artery. In procedural success was $100 \%$ with Post PCI TIMI flow III fig-2.

There was $80 \%$ complication free radial approach, only 8 patients $(16 \%)$ complaints of pain after procedure, $2(4 \%)$ had hematoma less than $5 \mathrm{~cm}$ and no major bleeding complication leading to blood transfusion fig-3.

\section{DISCUSSION}

Primary PCI was first introduced by American Cardiologist, Geoffrey Hartzler, in
1983. Primary PCI is now considered as the standard option of mechanical reperfusion for acute myocardial infarction necessitating experienced interventional cardiologists, cardiac surgical back

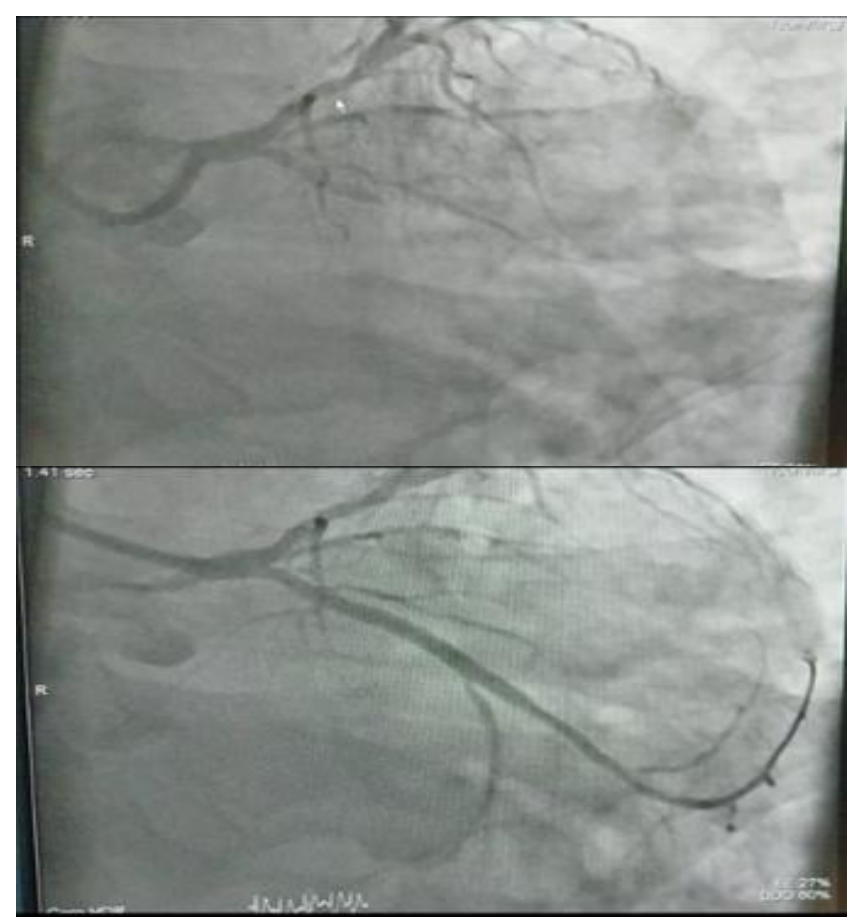

Figure-2: Procedural success with TIMI flow 3.

up and 24 hours/ 7 days catherization facilities ${ }^{17}$.

PPCI is offered to patient who presents to PCI capable setting within 90 minutes of typical chest pain or could be transferred to PCI capable

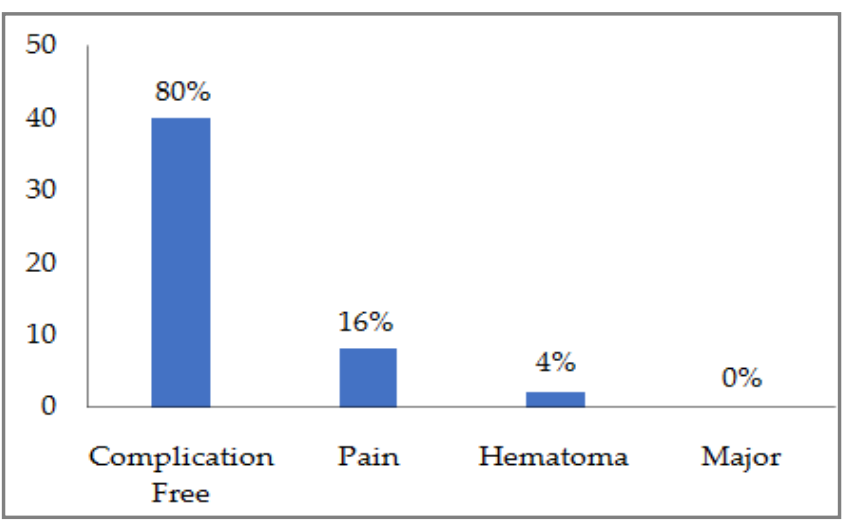

Figure-3: Description of complications $(n=50)$.

setting within 120 minutes. If PPCI couldn't be performed, then fibrinolytic therapy should be administered within 30 minutes $^{18}$. 
According to 2015 guidelines of management of Acute STEMI by European Society of cardiology, PPCI is class 1 indication for treatment of STEMI and favours transradial approach as access site for the procedure ${ }^{8}$. Conventionally, transfemoral approach is better option for interventionists. The main reason for their choice was better support by femoral artery for heavy wires, rota-ablation, kissing balloon and crush techniques. However, in primary PCI there are less likely chance of such bulky calcific lesions or complex bifurcations which need such techniques or equipment. Therefore, radial approach gained popularity and proved to be a safe option for PPCI. Our institution Army Cardiac center is a high-volume center for Myocardial infarction patients where we have recently started to offer all appropriate patients PPCI via radial Artery access and proved to be a safe and effective approach with $96 \%$ success rate and $80 \%$ complication free procedure outcomes of TRA. Such result corelates with HORIZON-AMI trial which showed advantage of TRA and less event free primary PCI procedure ${ }^{19}$.

In the current study we adopted to approach all patients with radial artery preferably right side. Only in one patient we need to switch to left radial artery because she had a wound with infective granulation tissue visible on right wrist and distal forearm. Procedure was done successfully from left side as well. Several data from published study showed that there is not much difference in the success rate from right or left side approach ${ }^{20}$. Anyhow, left radial access is favourable in certain patients who have propensity of radial artery tortuosity like people thin lean body, short stature, female gender and elderly patients ${ }^{21}$. On the other hand, in the present study, failed radial artery access leads to switching to transfemoral and homolateral ulnar approach $(4 \% \mathrm{v} / \mathrm{s} 2 \%)$ Jing et al, demonstrated the main cause for failure of transradial approach includes unsuccessful radial artery puncture (30\%) followed by vascular abnormality (47\%) and catheter related hinderance $(23 \%)^{22}$.
Primary PCI bleeding complications may lead to worse outcomes including higher incidence of morbidity and mortality. The main reason for bleeding could be due to administration of high dose of anticoagulants or access site related bleeding which accounts for half of the causes of bleeding. Strong correlation between bleeding, mortality and ischemia related complications have drawn attention to adopt appropriate strategies to avoid such incidences. Among novel approaches TRA significantly decreases bleeding risk. In our study there was $0 \%$ major bleed requiring blood transfusion however hematoma $(<5 \mathrm{~cm})$ was evident in $4 \%$ patients which resolved after local compression. Numerous renowned trials including Rival, Rifle-Staecs, Matrix, Stemi Radial proved major reduction in bleeding events, vascular site complications and all cardiac and other mortality downgrading in TRA as compared TFA $^{23}$.

Pain at the site of vascular access is the only main complication which occurred in our study group i.e. $16 \%$ which resolved with painkillers.

The main criticism encountered for radial artery access has always been expecting to be 'delayed door to balloon (D2B) time'. Haq et al, 2015 demonstrated in their study that there is longer D2B time in TRA as compared to TFA ${ }^{21}$, and this was the vital reason for cardiologist to be reluctant to adopt TRA. According to Joint Commission on Accreditation of Healthcare Organization, the main goal to achieve in PCI centre should be less than 90 minutes in order to salvage myocardium and better outcomes ${ }^{24-25}$. But with the passage of time, practice and expertise in operators, this time had been reduced. As in 2010, it was 64 mins, then a local study conducted in Rawalpindi, 2014 showed 54.1 minutes 26 and now in our study it is 34 minutes 2020.

The limitation of our pilot study is relatively small population size from a single centre. In future large-scale studies are required toelucidate our results. Additionally, common complication from Radial artery occlusion after procedure 
before discharged is unnoticed and need to be addressed.

\section{CONCLUSION}

Our study highlighted the fact that TRA is an easy and safe approach which showed outstanding results in our set up, in terms of less bleeding, early ambulation, less hospital stay leading to cost effectivity for patient as well as for hospital.

\section{CONFLICT OF INTEREST}

This study has no conflict of interest to be declared by author.

\section{REFERENCES}

1. Jamee Shahwan A, Abed Y, Desormais I. Epidemiology of coronary artery disease and stroke and associated risk factors in Gaza community -Palestine. PLOS One 2019; 14(1): e0211131.

2. World Health Statistics 2011 [Internet]. WHO. Available from: http://www.who.int/whosis/whostat/ 2011/en/.

3. Zubair F, Nawaz SK, Nawaz A. Prevalence of cardiovascular diseases in Punjab, Pakistan: a cross-sectional study. J Public Health (Berl) 2018; 26(1): 523-29.

4. Iqbal R, Jahan N, Hanif A. Epidemiology and Management Cost of Myocardial Infarction in North Punjab, Pakistan. Iran Red Crescent Med J 2015; 17(7): e13776-80.

5. Zubaid M, Khraishah H, Alahmad B, Rashed W, Ridha M, Alenezi $\mathrm{F}$, et al. Efficacy and safety of pharmacoinvasive stra-tegy compared to primary percutaneous coronary intervention in the management of st-segment elevation myocardial infarc-tion: a prospective country-wide registry. Ann Global Health 2020; 86(1): 13-15.

6. Patrick T, Frederick GO, Deborah DK, Donald EA, Mina KC, James AC, et al. A Report of the American College of Cardiology Foundation/American Heart Association Task Force on practice guidelines. No. 42013 ACCF/AHA guideline for the manage-ment of ST-Elevation. Originally Published 2013; 127(1): e362-25.

7. Roffi M, Patrono C, Collet JP, Mueller C, Valgimigli M. ESC Scientific Document Group2015 ESC Guidelines for the management of acute coronary syndromes in patients presenting with-out persistent ST-segment elevation: task force for the manage-ment of acute coronary syndromes in patients presenting with-out persistent ST-segment elevation of the European society of cardiology (ESC). Eur Heart J 2016; 37(3): 267-31.

8. Anjum I, Khan MA, Aadil M, Faraz A, Farooqui M, Hashmi A. Transradial vs. transfemoral approach in cardiac catheterization: A literature review. Cureus 2017; 9(6): e130912.

9. Slawin J, Kubler P, Szczepanski A, Piątek J, Stępkowski M, Reczuch K. Radial artery occlusion after percutaneous coronary interventions-an underestimated issue Postep Kardiol Inter 2013; 9(4): 353-61.
10. Aamir S, Mohammed S, Sudhir R. J Geriatr Transradial approach for coronary procedures in the elderly population Cardiol 2016; 13(1): 798-06.

11. Jang JS, Jin HY, Seo JS, Jang JS, Jin HY, Seo JS. The transradial versus the transfemoral approach for primary percutaneous cor-onary intervention in patients with acute myocardial infarction: a systematic review and metaanalysis. Eur Assoc Percutaneous Cardiovas Interv 2012; 8(1): 501-10.

12. The transradial versus the transfemoral approach for primary percutaneous coronary intervention in patients with acute myocardial infarction: a systematic review and metaanalysis. EAPCI 2012; 8(1): 501-10.

13. Olivier F, Sunil VB, Samir R, Sanjit SP, Josep J, Eric Larose $\mathrm{RC}$, et al. Transradial approach for coronary angiography and inter-ventions: results of the first international transradial practice survey. JACC Cardiovasc Interv 2010; 3(10): 1022-31.

14. Neumann EJ, Sousa-Uva M, Ahlsson A, Alfonso F, Adrian P, et al, ESC/EACTS Guidelines on myocardial revascularization. European Heart J 2018; 40(2): Pages 87-165.

15. Transradial Access in Primary PCI on the Upswing in the US but Still Uneven. Available from: https://www.tctmd.com/ news/transradial-access-primary-pci-upswing-us-stilluneven.

16. Jae-Sik J, Han-Young J, Jeong-Sook S, Tae-Hyun Y, DaeKyeong K, Kim DK, et al. The transradial versus the transfemoral approach for primary percutaneous coronary intervention in patients with acute myocardial infarction: A systematic review and meta-analysis. EuroIntervention: Journal of Eurpeon PCR in collaboration with the working group on interventional cardio-logy of the European Society of Cardiology. EuroIntervention 2012; 8(4): 501-10.

17. Cannon CP. Evolving management of ST-segment elevation myocardial infarction: update on recent data. Am J Cardiol 2006; 98(1): 10-21.

18. Akbar H, Foth C, Kahloon RA. Acute Myocardial Infarction ST Elevation (STEMI) [Updated 2020 Jan 31]. In: StatPearls [Internet]. Treasure Island (FL): Stat Pearls Publishing; 2020 Jan. Available from: https://www.ncbi.nlm.nih.gov/books/ NBK532281/

19. Kedev S. The Role of the Transradial Approach for Complex Coronary Interventions in Patients with Acute Coronary Syndrome. Interv Cardiol 2013; 8(2): 81-86.

20. Fu Q, Hu H, Wang D, Wei Chen W, Tan Z, Li Q, et al. Buxing Chen Author information Copyright and License information Disclaimer et al. Randomized comparative study of left versus right radial approach in the setting of primary percutaneous coronary intervention for STelevation myocardial infarction. Clin Interv Aging 2015; 10(1): 1003-08.

21. Heshmat H, Haddad YE, Farouk M. Mohamed abdel meguid radial access in primary PCI for acute myocardial infarction. Published: June 28th 2017, DOI:10.5772/ intechopen.69131

22. Hu J, Cai X, Wang X, Chen L, Xu D, Li J. Risk factors of failed transradial approach for percutaneous coronary interventions in Chaoshan Chinese: a locally retrospective analysis. Int J Clin Exp Med 2015; 8(7): 11770-76. 
23. Kalra S, Bhatt H. Stenting in primary percutaneous coronary intervention for acute ST-segment elevation myocardial infarction. Methodist Debakey Cardiovasc J 2018; 14(1): 14-22.

24. Krumholz HM, Herrin J, Miller LE, Drye EE, Ling SM, Han LF, et al. Improvements in door-to-balloon time in the
United States, 2005 to 2010. Circulation 2011; 124(9): 1038-45. 25. Bradley EH, Nallamothu BK, Herrin J, Ting HH, Stern AF, Nembhard IM, et al. National efforts to improve door-toballoon time results from the Door-to-Balloon Alliance. J Am Coll Cardiol 2009; 54(25): 2423-29. 